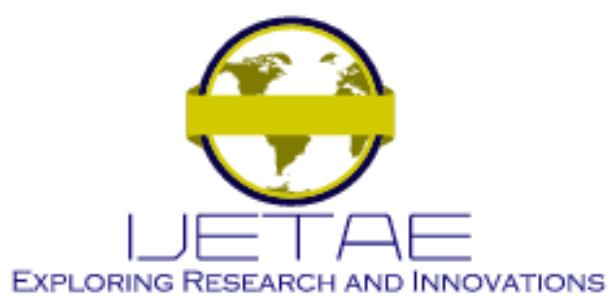

International Journal of Emerging Technology and Advanced Engineering

Website: www.ijetae.com (E-ISSN 2250-2459, Scopus Indexed, ISO 9001:2008 Certified Journal, Volume 11, Issue 10, October 2021)

Manuscript Received: 04 September 2021, Received in Revised form: 06 October 2021, Accepted: 15 October 2021 DOI: 10.46338/ijetae1021_20

\title{
Comparative Study on the Attributes Analysis of Software Development Cost Model Based on Exponential-type Lifetime Distribution
}

\author{
Tae-Jin Yang \\ Professor, Department of Electronic Engineering, Namseoul University, Cheonan, 31020, South Korea
}

\begin{abstract}
In this paper, the development cost attributes were newly analyzed by applying the Exponential-type lifetime distributions (Burr-Hatke-exponential, ExponentialBasic, Exponential-exponential, Inverse-exponential) widely utilized in the field of software lifetime testing and quality evaluation to the software development cost model. Also, to verify the attributes of the analyzed development cost, after analyzing the future reliability, the optimal cost model was presented.

For this study, an analysis algorithm using software failure time data was proposed to solve the research solution, the maximum likelihood estimation (MLE) was applied to solve the parameter values, and the nonlinear equation was calculated using the binary method. Simulations show that if the cost of removing one flaw found during the test phase increases, the development cost increases, but the release time does not change. However, if the cost of flaws correction discovered by operators increased, both development costs and release times increased. Therefore, we must remove all possible flaws at the testing stage to eliminate failures. In conclusion, First, the Exponential-exponential distribution model showed the best performance among the proposed models because it had the lowest software development cost and the highest future reliability. Second, the software development cost attributes of the Exponential-type lifetime distributions were newly analyzed. Third, through this data, it was able to help software developers to analyze the most economical development cost.
\end{abstract}

Keywords - Burr-Hatke-exponential, Exponentialexponential, Exponential-type distribution, Inverseexponential, Future Reliability, Software Development Cost

\section{INTRODUCTION}

Unlike the era of the 3rd industrial revolution when only internet-based technologies such as internet home shopping and online banking were used, in the current 4th industrial revolution era based on digital convergence technology, the most important thing is to develop reliable software that can accurately process large amounts of data that can be applied in various industrial fields without failure.
In the process of developing such reliable software, the most important topic is research on development cost. Therefore, software developers and researchers have been doing a lot of research to find a way to develop reliable software at an economical cost [1]. In particular, Yang [2] presented a study on the property of the software reliability model using Type-2 Gumbel and Erlang lifetime distribution based on the non-homogeneous Poisson process (NHPP) model. Pham [3] presented a new type of distribution function using the failure rate function. Banga and Bansal, Singh [4] proposed a new analysis method using a hybrid approach to predict software fault detection. Also, Dohi and Suzuki, Osaki [5] performed the property analysis of software cost models with periodic/non-periodic examples. Also, Pham and Zhang [6] analyzed and presented the correlation of the NHPP software reliability model and cost model. Kim and Shin [7] performed the property study of software optimal release time using Gamma distribution and the Non-Exponential family distribution. Also, Kim [8] presented a study on the attributes of the software development cost model based on shape parameter of the NHPP Weibull distribution model.

Therefore, in this study, after applying the Exponentialtype lifetime distributions which are widely utilized in the field of reliability tests to the finite failure NHPP software reliability model, we will newly analyze the cost attributes by using the proposed software development model.

\section{RELATED WORKS}

\section{A. NHPP Model and NHPP Software Reliability Model a) NHPP model}

The NHPP model is a stochastic distribution model in which the number of occurrences $\mathrm{N}(\mathrm{t})$ at time $\mathrm{t}$ follows a Poisson distribution with parameters.

Mainly, it is useful for modeling permutations in which the number of mutually independent events occurs steadily over time. 


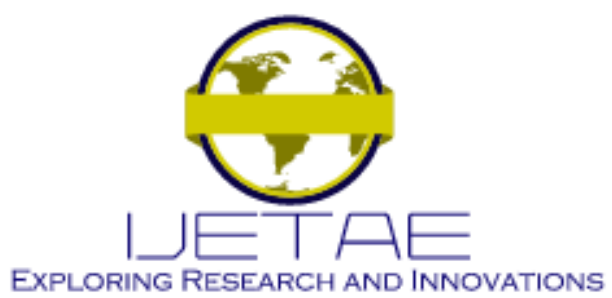

International Journal of Emerging Technology and Advanced Engineering

Website: www.ijetae.com (E-ISSN 2250-2459, Scopus Indexed, ISO 9001:2008 Certified Journal, Volume 11, Issue 10, October 2021)

In the NHPP model, $\mathrm{N}(\mathrm{t})$ refers to the accumulated number of software flaws detected up to the test time $t$, and $\mathrm{m}(\mathrm{t})$ refers to the expected value at which flaws can occur. Therefore, the NHPP model is as follows.

$P\{N(t)=n\}=\frac{[m(t)]^{n} \cdot e^{-m(t)}}{n !}$

Note. $\mathrm{n}=0,1,2, \cdots \infty$.

Thus, the NHPP model contains property about mean value $m(t)$ and intensity pattern $\lambda(t)$ as below.

$$
m(t)=\int_{0}^{t} \lambda(s) d s
$$

$\frac{d m(t)}{d(t)}=\lambda(t)$

\section{b) NHPP Software Reliability model}

We will use the NHPP software reliability model with software failure time based on the NHPP model to analyze the attributes of software development costs.

The time-domain NHPP model is divided into a finite failure which means that no more failures occur when repairing a failure, and an infinite failure in which failures can continue to occur even when repairing a failure.

In this study, we will analyze based on the finite failure cases.

In the finite failure NHPP model, if $\mathrm{f}(\mathrm{t})$ is a probability density function and $F(t)$ is a cumulative distribution function, then the average value function $m(t)$ and the intensity function $\lambda(t)$ are as follows [9].

$$
\begin{aligned}
& m(t \mid \theta, b)=\theta F \\
& \lambda(t \mid \theta, b)=\theta F(t)^{\prime}=\theta f(t)
\end{aligned}
$$

Therefore, the likelihood function is as follows [9].

$$
L_{N H P P}(\Theta \mid \underline{x})=\left(\prod_{i=1}^{n} \lambda\left(x_{i}\right)\right) \exp \left[-m\left(x_{n}\right)\right]
$$

Note. $\underline{x}=\left(x_{1}, x_{2}, x_{3} \cdots x_{n}\right)$.

\section{B. Exponential-Basic: Finite Failure NHPP Model}

Among the models widely applied and utilized in reliability testing, the basic type is the Goel-Okumoto model whose lifetime distribution follows the exponential distribution.

When the Exponential-Basic distribution is applied to the NHPP reliability model as shown in Eq. 4 and Eq. 5, it is as follows [10].

$$
\begin{aligned}
& m(t \mid \theta, b)=\theta F(t)=\theta\left(1-e^{-b t}\right) \\
& \lambda(t \mid \theta, b)=\theta f(t)=\theta b e^{-b t}
\end{aligned}
$$

Note that $\theta>0, b>0$.

After substituting Eq. 7 and Eq. 8 into Eq. 6, if taking the logarithm of both sides, then the log-likelihood function can be solved as follows.

$$
\begin{aligned}
\ln L_{N H P P}(\theta \mid \underline{x}) & =n \ln \theta+n \ln b-b \sum_{k=1}^{n} x_{k} \\
& -\theta\left(1-e^{-b x_{n}}\right)
\end{aligned}
$$

If the partial derivatives of the parameters $\theta$ and $b$ are obtained, then parameters $\hat{\theta}_{M L E}$ and $\hat{b}_{M L E}$ can be solved by the binary method as below.

$$
\begin{aligned}
& \frac{\partial \ln L_{N H P P}(\Theta \mid \underline{x})}{\partial \theta}=\frac{n}{\hat{\theta}}-1+e^{-\hat{b} x_{n}}=0 \\
& \frac{\partial \ln L_{N H P P}(\Theta \mid \underline{x})}{\partial b}=\frac{n}{\hat{b}}-\sum_{i=1}^{n} x_{i}-\hat{\theta} \hat{b} x_{n} e^{-\hat{b} x_{n}}=0
\end{aligned}
$$

C. Exponential-exponential lifetime distribution: Finite Failure NHPP Model

Among the software reliability models, a particular type of the Weibull exponential distribution is the exponential-exponential distribution.

When the Exponential-exponential lifetime distribution is applied to the NHPP reliability model as shown in Eq. 4 and Eq. 5, it is as follows.

$$
\begin{aligned}
& m(t \mid \theta, a, b)=\theta F(t)=\theta\left[1-\exp \left(-a e^{b t}+a\right)\right] \\
& \lambda(t \mid \theta, a, b)=\theta f(t)=\theta\left[a b \exp \left(b t-a e^{b t}+a\right)\right]
\end{aligned}
$$




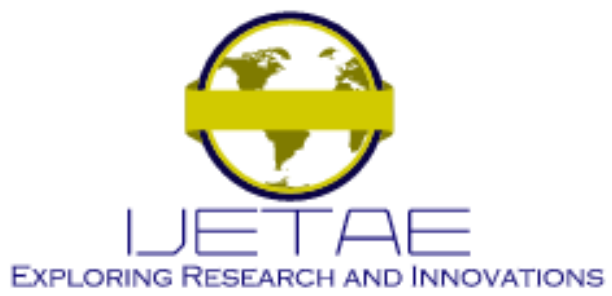

International Journal of Emerging Technology and Advanced Engineering

Website: www.ijetae.com (E-ISSN 2250-2459, Scopus Indexed, ISO 9001:2008 Certified Journal, Volume 11, Issue 10, October 2021)

Therefore, the log-likelihood function is as follows.

$$
\begin{aligned}
\ln L_{N H P P}(\Theta \mid \underline{x})=-\hat{\theta}\left[1-\exp \left(-a e^{\hat{b} x_{n}}+a\right)\right] \\
+\sum_{i=1}^{n} \ln \left[\hat{\theta}\left(a b \exp \left(b x_{i}-a e^{b x_{i}}+a\right)\right)\right]
\end{aligned}
$$

Note that $\Theta=\{\theta, a, b\}$ is the parameter space.

If the partial derivatives of the parameters $\theta$ and $b$ are obtained, then the parameters $\hat{\theta}_{M L E}$ and $\hat{b}_{M L E}$ can be solved by the binary method as below.

$$
\begin{gathered}
\frac{\partial \ln L_{N H P P}(\Theta \mid \underline{x})}{\partial \theta}=\frac{n}{\hat{\theta}}-\left[1-\exp \left(-2 e^{\hat{b} x_{n}}+2\right)\right]=0( \\
\frac{\partial \ln L_{N H P P}(\Theta \mid \underline{x})}{\partial b}=\frac{n}{b}+\sum_{i=1}^{n} x_{i}-2 \sum_{i=1}^{n} x_{i} e^{b x_{i}} \\
-2 \hat{\theta} x_{n} \exp \left(b x_{n}-2 x_{n} e^{6 x_{n}}+2\right)=0
\end{gathered}
$$

Note that $\mathrm{x}=\left(\mathrm{x}_{1}, \mathrm{x}_{2,}, \mathrm{x}_{3} \cdots \mathrm{x}_{\mathrm{n}}\right)$.

\section{Inverse-exponential lifetime distribution: Finite Failure NHPP Model}

The Inverse-Weibull distribution is widely utilized distribution in the reliability lifetime test. Here, the Inverseexponential distribution is got when the shape parameter( $($ ) is 1 . Thus, the cumulative distribution function $F(t)$ of the Inverse-Weibull distribution is as follows [11].

$F(\mathrm{t})=e^{-(b t)^{-\gamma}}$

Note that $\gamma$ is a shape parameter.

Where, if the Inverse-exponential lifetime distribution is applied to the NHPP reliability model as shown in Eq. 4 and Eq. 5, it is as follows.

$$
\begin{aligned}
& \mathrm{m}(\mathrm{t} \mid \theta, \mathrm{b})=\theta F(\mathrm{t})=\theta e^{-(b t)^{-1}} \\
& \lambda(\mathrm{t} \mid \theta, \mathrm{b})=\theta \mathrm{f}(\mathrm{t})=\theta b^{-1} t^{-2} e^{-(b t)^{-1}}
\end{aligned}
$$

Therefore, the log-likelihood function is as follows.

$$
\begin{aligned}
\ln L_{N H P P}(\theta \mid \underline{x})= & n \ln \theta-n \ln b+2 \sum_{i=1}^{n} x_{i}-\sum_{i=1}^{n}\left(b x_{i}\right)^{-1} \\
& -\hat{\theta} e^{-\left(b x_{n}\right)^{-1}}=0
\end{aligned}
$$

The partial derivatives of the parameter and are as follows.

$$
\begin{aligned}
\frac{\partial \ln L_{\text {NHPP }}(\Theta \mid \underline{x})}{\partial \theta}= & \frac{n}{\hat{\theta}}-e^{-\left(b x_{n}\right)^{-1}}=0 \\
\frac{\partial \ln L_{\text {NHPP }}(\Theta \mid \underline{x})}{\partial b}= & -\frac{n}{\hat{b}}+\frac{1}{b^{2}} \sum_{i=1}^{n} \frac{1}{x_{i}} \\
& -\theta \frac{1}{b^{2} x_{n}} e^{-\left(b x_{n}\right)^{-1}}=0
\end{aligned}
$$

Note that $x=\left(x_{1}, x_{2}, x_{3} \cdots x_{n}\right)$.

E. Burr-Hatke-exponential lifetime distribution: Finite Failure NHPP Model

The Burr-Hatke-exponential distribution is widely utilized in the field of software reliability testing because the pattern of the hazard function increases or decreases.

Where, the Burr-Hatke-exponential lifetime distribution is applied to the NHPP reliability model as shown in Eq. 4 and Eq. 5, it is as follows.

$$
\begin{aligned}
& m(t \mid \theta, b)=\theta F(t)=\theta\left[1-\frac{e^{-b t}}{1+b t}\right] \\
& \lambda(t \mid \theta, b)=\theta f(t)=\theta\left[b e^{-b t} \frac{2+b t}{(1+b t)^{2}}\right]
\end{aligned}
$$

Note. $a, b>0, t \in[0, \infty]$

After substituting Eq. 23 and Eq. 24 into Eq. 6, if taking the logarithm of both sides, then the log-likelihood function can be solved [12]. Therefore, the partial derivatives of the parameter $\theta$ and $\mathrm{b}$ are as follows. 


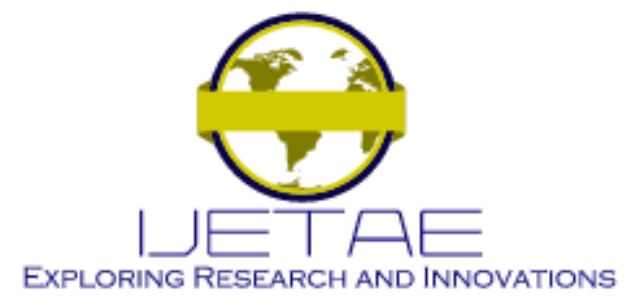

International Journal of Emerging Technology and Advanced Engineering

Website: www.ijetae.com (E-ISSN 2250-2459, Scopus Indexed, ISO 9001:2008 Certified Journal, Volume 11, Issue 10, October 2021)

$$
\begin{aligned}
& \frac{\partial \ln L_{N H P P}(\Theta \mid \underline{x})}{\partial \theta}=\frac{n}{\hat{\theta}}-\left(1-\frac{e^{-b x_{n}}}{1+b x_{n}}\right)=0 \\
& \frac{\partial \ln L_{N H P P}(\Theta \mid \underline{x})}{\partial b}=\frac{n}{\hat{b}}-\sum_{i=1}^{n} x_{i}-\sum_{i=1}^{n} \frac{x_{i}}{2+b x_{i}} \\
& -2 \sum_{i=1}^{n} \frac{x_{i}}{1+b x_{i}}-\hat{\theta} x_{n} e^{-b x_{n}} \frac{2+b x_{i}}{\left(1+b x_{i}\right)^{2}}=0
\end{aligned}
$$

Note. $x=\left(x_{1}, x_{2}, x_{3} \cdots x_{n}\right)$.

\section{F. Software Development Cost Model}

The software development cost model using the mean function $m(t)$ is as follows [13].

$$
\begin{aligned}
E_{t}= & E_{1}+E_{2}+E_{3}+E_{4}=E_{1}+C_{2} \times t+C_{3} \times m(t) \\
& +C_{4} \times\left[m\left(t+t^{\prime}\right)-m(t)\right]
\end{aligned}
$$

Note that $E_{t}$ is the total cost of software development.

(1) $E_{1}$ is initial development costs.

(2) $\mathrm{E}_{2}$ is the testing cost per unit time.

$$
E_{2}=C_{2} \times t
$$

Note that $C_{2}$ is the testing cost per unit time.

(3) $\mathrm{E}_{3}$ is the cost of removing one flaw.

$$
E_{3}=C_{3} \times m(t)
$$

Note that $C_{a}$ refers to the cost of removing one flaw found in the test stage before releasing the software, and $m(t)$ refers to the average value function.
(4) $E_{4}$ is the cost of removing all remaining flaws in the operating stage.

$$
E_{4}=C_{4} \times\left[m\left(t+t^{\prime}\right)-m(t)\right]
$$

Note that $C_{4}$ is the flaw correction cost found in the software operation stage, and $t^{t}$ refers to the time during which the software system can operate normally after the software is released.

\section{Solutions By The AnAlysis Algorithm Using SOFTWARE FAILURE TIME DATA}

In this study, the proposed algorithm for analyzing and predicting software development costs is as follows.

Development cost analysis algorithm:

Step 1: Verification of software failure data collected during desktop application operation.

Step 2: Calculating the reliability attributes parameters

$\left(\hat{\theta}_{M L E}, \hat{b}_{M L E}\right)$ for the proposed models.

Step 3: Calculating the software development $\operatorname{cost}\left(E_{\mathrm{t}}\right)$ using the mean value function.

Step 4: Analyzing the results of changing the cost attributes $\left(\mathrm{C} 2, \mathrm{C} 3, \mathrm{C} 4, t^{t}\right)$ that make up the software

development cost.

Step 5: Analyzing the future reliability attributes $\hat{R}(t)$ of the proposed models by using the mean value function.

Step 6: Determining the best performance model that meets both development cost and future reliability.

The software failure time data used in this paper is shown in Table 1 [14]. 


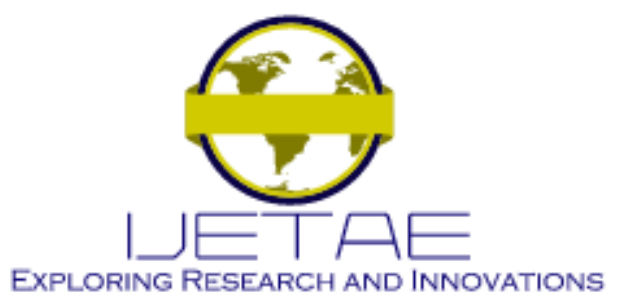

International Journal of Emerging Technology and Advanced Engineering

Website: www.ijetae.com (E-ISSN 2250-2459, Scopus Indexed, ISO 9001:2008 Certified Journal, Volume 11, Issue 10, October 2021)

Table 1

Software Failure Time Data

\begin{tabular}{|c|c|c||c|c|c|}
\hline $\begin{array}{c}\text { Failure } \\
\text { Number }\end{array}$ & $\begin{array}{c}\text { Failure Time } \\
\text { (hours) }\end{array}$ & $\begin{array}{c}\text { Failure Time } \\
\text { (hours) } \\
\times \mathbf{1 0}^{-2}\end{array}$ & $\begin{array}{c}\text { Failure } \\
\text { Number }\end{array}$ & $\begin{array}{c}\text { Failure Time } \\
\text { (hours) }\end{array}$ & $\begin{array}{c}\text { Failure Time } \\
\text { (hours) } \times \mathbf{1 0}^{-2}\end{array}$ \\
\hline \hline 1 & 30.02 & 16 & 151.78 & 1.51 \\
\hline 2 & 31.46 & 0.31 & 17 & 177.50 & 1.77 \\
\hline 3 & 53.93 & 0.53 & 19 & 182.21 & 1.80 \\
\hline 4 & 55.29 & 0.55 & 20 & 186.34 & 1.86 \\
\hline 5 & 58.72 & 0.58 & 21 & 256.81 & 2.56 \\
\hline 6 & 71.92 & 0.71 & 22 & 273.88 & 2.73 \\
\hline 7 & 77.07 & 0.77 & 23 & 277.87 & 2.77 \\
\hline 8 & 80.90 & 0.80 & 24 & 453.93 & 4.53 \\
\hline 9 & 101.90 & 1.01 & 25 & 535.00 & 5.35 \\
\hline 10 & 114.87 & 1.14 & 26 & 537.27 & 5.37 \\
\hline 11 & 115.34 & 1.15 & 27 & 552.90 & 5.52 \\
\hline 12 & 121.57 & 1.21 & 1.24 & 673.68 & 704.49 \\
\hline 13 & 124.97 & 1.34 & 1.36 & 738.68 & 7.04 \\
\hline 14 & 134.07 & 136.25 & 28 & & 7.38 \\
\hline
\end{tabular}

A. Step 1: verification of software failure data collected during desktop application operation.

The failure time data used in this paper means random failures caused by software design and analysis errors and insufficient testing during the normal operation of desktop applications. Therefore, in this study, Laplace trend test was applied to determine the availability of the collected failure time data.

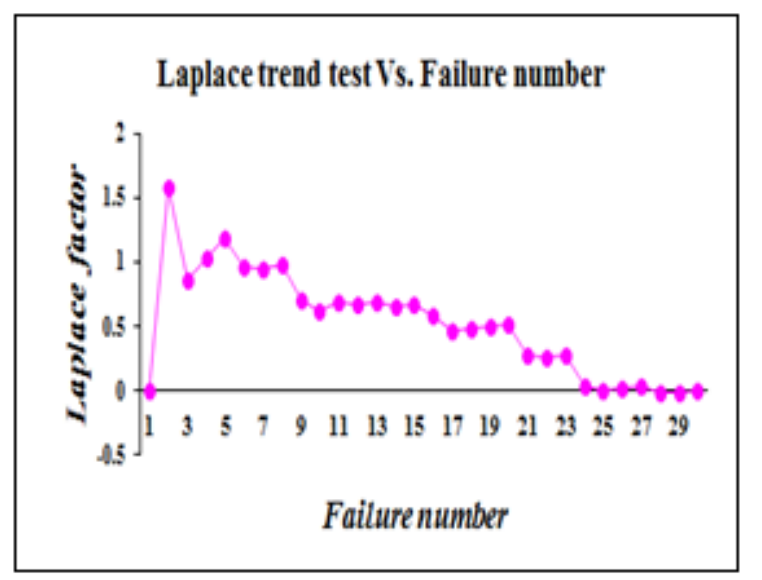

Figure 1. Estimation Results of Laplace Trend Test 


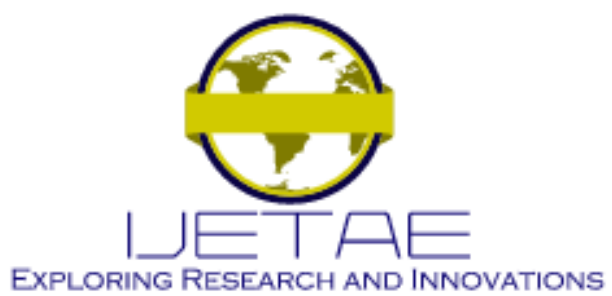

International Journal of Emerging Technology and Advanced Engineering

Website: www.ijetae.com (E-ISSN 2250-2459, Scopus Indexed, ISO 9001:2008 Certified Journal, Volume 11, Issue 10, October 2021)

As shown in Figure 1, the estimated result of the Laplace trend test existed between 0 and 2 [15]. Therefore, this failure data can be applied because there are no extreme values.

\section{B. Step 2: Calculating the reliability attributes}

Parameters $\left(\hat{\theta}_{M L E}, \hat{b}_{M L E}\right)$ for the proposed models.

Where, $\theta$ is the expected value of software flaw that can be found at the observing time $(0, \mathrm{t}), b$ is the shape parameter that means the shape of failure occurring.

The maximum likelihood estimation (MLE) was applied to calculate parameter estimation [16].

And to facilitate parameter estimation, numerical conversion data was used. Table 2 below shows the parameter estimation result of the proposed models.
C. Step 3: Calculating the software development cost $\left(E_{t}\right)$ using the mean value function.

The calculating method of the mean value function that determines the software development cost is shown in Table 3 [17].

Also, the estimated result value of mean value function $m(t)$ is shown in Table 4.

D. Step 4: Analyzing the results of changing the cost attributes $\left(C 2, C 3, C 4, t^{\prime}\right)$ that make up the software development cost.

In this study, to test the same development conditions, the software development cost is presented as [Assumption 1] [Assumption 5].

Table 2

Parameter Estimation Result of the Proposed Models

\begin{tabular}{|c||c||c|c|}
\hline \multicolumn{1}{|c||}{ Type } & \multicolumn{2}{c|}{$\begin{array}{c}\text { MLE } \\
\text { NHPP Model } \\
\text { (Maximum Likelihood Estimation) }\end{array}$} \\
\hline \hline \multirow{2}{*}{$\begin{array}{c}\text { Basic Model } \\
\text { Exponential-type } \\
\text { Lifetime } \\
\text { Distribution }\end{array}$} & Exponential-Basic & $\hat{\theta}=33.409$ & $\hat{\mathrm{b}}=0.309$ \\
\cline { 2 - 3 } & Burr-Hatke-exponential & $\hat{\mathrm{t}}=32.241$ & $\hat{\mathrm{b}}=0.495$ \\
& Exponential-exponential & $\hat{\theta}=30.598$ & $\hat{\mathrm{b}}=1.810$ \\
\hline
\end{tabular}

a) [Assumption 1: basic conditions]

$$
E_{1}=50 \$, C_{2}=5 \$, C_{3}=1.5 \$, C_{4}=10 \$, t^{\prime}=50 \mathrm{H}
$$

Figure 2 shows the development cost simulation results using [Assumption 1]. 


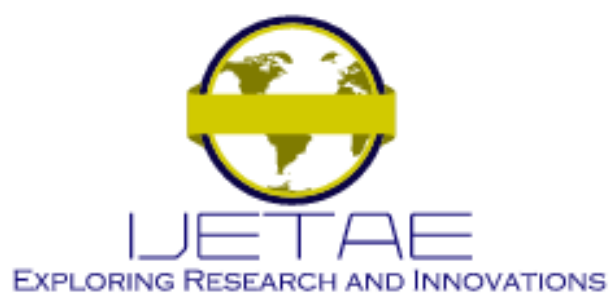

International Journal of Emerging Technology and Advanced Engineering

Website: www.ijetae.com (E-ISSN 2250-2459, Scopus Indexed, ISO 9001:2008 Certified Journal, Volume 11, Issue 10, October 2021)

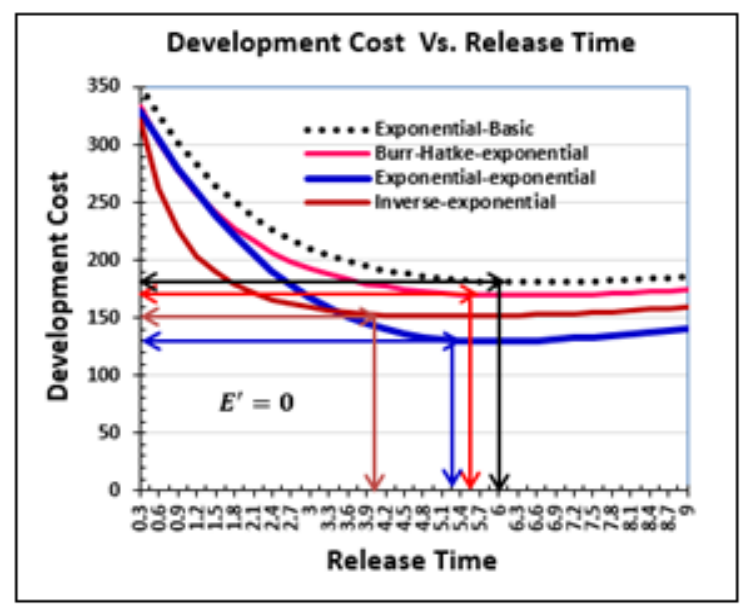

Analyzing the simulation results in Figure 2, it can be seen that the shape of the development cost test curve gradually increases with time passing.

The reason is that the probability of finding the remaining flaws at the latter stage gradually decreases. In the end, it means that the development cost increases even more towards the latter stage [18].

As shown in Figure 2, the exponential-exponential model showed the best performance among the proposed models because of the lowest development cost and relatively fast release time.

Figure 2. The Development Cost Test Simulated by [Assumption 1]

Table 3

Software Development Cost Model and Mean Value Function

\begin{tabular}{|c|c|c|c|}
\hline Type & NHPP Model & $\begin{array}{c}m(t) \text { of Exponential-type Lifetime } \\
\text { Distribution }\end{array}$ & $\begin{array}{c}m(t) \text { of Software } \\
\text { Development Cost Model }\end{array}$ \\
\hline Basic Model & Exponential-Basic & $m(t)=\theta\left(1-e^{-b t}\right)$ & \multirow{4}{*}{$\begin{aligned} E_{3} & =C_{3} \times m(t) \\
E_{4} & =C_{4} \times\left[m\left(t+t^{\prime}\right)-m(t)\right]\end{aligned}$} \\
\hline \multirow{3}{*}{$\begin{array}{l}\text { Exponential-type } \\
\text { Lifetime } \\
\text { Distribution }\end{array}$} & Burr-Hatke-exponential & $m(t)=\theta\left[1-\frac{e^{-b t}}{1+b t}\right]$ & \\
\hline & Exponential-exponential & $m(t)=\theta\left[1-\exp \left(-a e^{b t}+a\right)\right]$ & \\
\hline & Inverse-exponential & $m(t)=\theta e^{-(b t)^{-1}}$ & \\
\hline
\end{tabular}




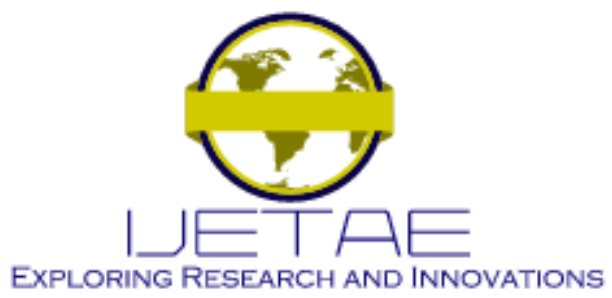

International Journal of Emerging Technology and Advanced Engineering

Website: www.ijetae.com (E-ISSN 2250-2459, Scopus Indexed, ISO 9001:2008 Certified Journal, Volume 11, Issue 10, October 2021)

Table 4

The Estimated Result Value of Mean Value Function m(t)

\begin{tabular}{|c|c|c|c|c|c|}
\hline \multirow{2}{*}{$\begin{array}{l}\text { Failure } \\
\text { Number }\end{array}$} & \multirow{2}{*}{$\begin{array}{c}\text { Release Time } \\
\text { (hours) }\end{array}$} & \multirow{2}{*}{$\begin{array}{c}\text { Basic-type } \\
\begin{array}{c}\text { Exponential - } \\
\text { Basic }\end{array}\end{array}$} & \multicolumn{3}{|c|}{ Exponential-type Lifetime Distribution } \\
\hline & & & $\begin{array}{l}\text { Burr-Hatke- } \\
\text { exponential }\end{array}$ & $\begin{array}{l}\text { Exponential- } \\
\text { exponential }\end{array}$ & $\begin{array}{l}\text { Ieverse- } \\
\text { exponeatial }\end{array}$ \\
\hline 1 & 0.3 & 3,90049458 & 4697852552 & 3.357564094 & 4269634291 \\
\hline 2 & 0.6 & 7.276973275 & 8.490708436 & 6.510429638 & 1139123187 \\
\hline 3 & 0.9 & 1019993553 & 1159289572 & 9.450691527 & 15.79903994 \\
\hline 4 & 12 & 127300229 & 14143576 & 1217267896 & 18,60632915 \\
\hline 5 & 1.5 & 149202997 & 1627401059 & 1467320264 & 20.52478998 \\
\hline 6 & 1.8 & 1681690289 & 18.05961218 & 16.95154958 & 2191243908 \\
\hline 7 & 2.1 & 18.45759427 & 1956245098 & 19.00956428 & 2296059281 \\
\hline 8 & 24 & 19.8783847 & 20.83636018 & 20.85160454 & 23.7796634 \\
\hline 9 & 27 & 21.10929761 & 2192052154 & 2248443647 & 24.43678325 \\
\hline 10 & 3.0 & 2217297663 & 2284702984 & 23.91705961 & 2497552946 \\
\hline 11 & 3.3 & 23.09462027 & 23.64175958 & 25.16046528 & 25.42514458 \\
\hline 12 & 3.6 & 23.99244476 & 2432573896 & 26.22733542 & 25.90600067 \\
\hline 13 & 3.9 & 2459309471 & 249161926 & 27.13169215 & 2613271611 \\
\hline 14 & 4.2 & 25.19093995 & 25.42731684 & 27.899512 & 26.41604914 \\
\hline 15 & 4.5 & 25.69847572 & 25.87089576 & 28.51332097 & 26.6640962 \\
\hline 16 & 4.8 & 2614649262 & 26.25671765 & 29.02178767 & 26.89302926 \\
\hline 17 & 5.1 & 2653430158 & 26.59304073 & 29.42933491 & 27.0777068 \\
\hline 18 & 5.4 & 25.87001961 & 26.89678205 & 29.79078318 & 27.25193671 \\
\hline 19 & 5.7 & 27.16065334 & 27.14379754 & 30,00004685 & 27.40877669 \\
\hline 20 & 6.0 & 27.41220525 & 27.36905663 & 3019999965 & 27.55070428 \\
\hline 21 & 6.3 & 27.62997943 & 27.56679132 & 30,33175132 & 27.67974912 \\
\hline 22 & 6.6 & 27.81349651 & 27.7006173 & 30,4356462 & 27.79759513 \\
\hline 23 & 69 & 27.98168708 & 27.99363302 & 30.51013246 & 27.9056135 \\
\hline 24 & 7.2 & 28.12295365 & 2802950109 & 30.56234527 & 28.00500828 \\
\hline 25 & 7.5 & 28.24524161 & 28.1475155 & 30.59908338 & 2809676412 \\
\hline 26 & 7.8 & 28.35110068 & 28.25265741 & 30.62193636 & 28.18172963 \\
\hline 27 & 8.1 & 28.442738 & 2834564169 & 30.63743901 & 28.26062954 \\
\hline 28 & 3.4 & 28.52206421 & 28.42795579 & 3064723223 & 2833409052 \\
\hline 29 & 8.7 & 28.59073327 & 28.50099244 & 30.65323958 & 28.40265781 \\
\hline 30 & 9.0 & 28,65017691 & 28.56557723 & 30.65690766 & 28.46690364 \\
\hline
\end{tabular}

b) [Assumption 2: Supposed that the cost is twice increased in Assumption 1]

$E_{1}=50 \$, C_{2}=10 \$, C_{3}=1.5 \$, C_{4}=10 \$, t^{\prime}=50 \mathrm{H}$

[Assumption 2] is a case where the software testing cost ( is twice increased in [Assumption 1].

The simulation results shown in Figure 3 show that development costs have increased but release time has not changed at all.

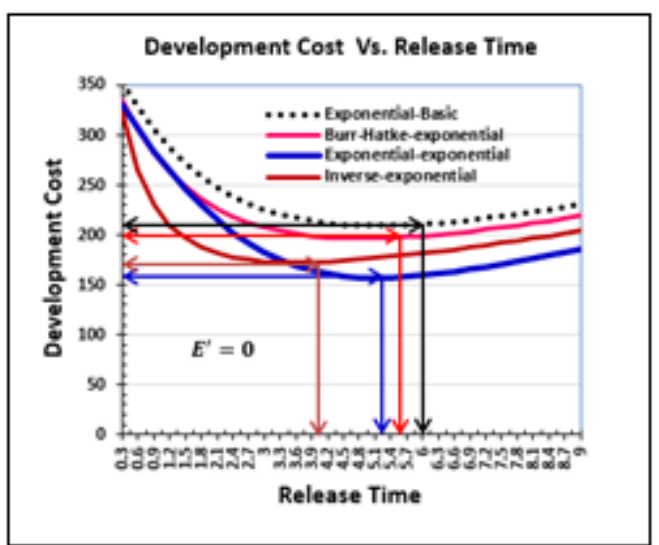

Figure 3 The Development Cost Test Simulated by [Assumption 2] 


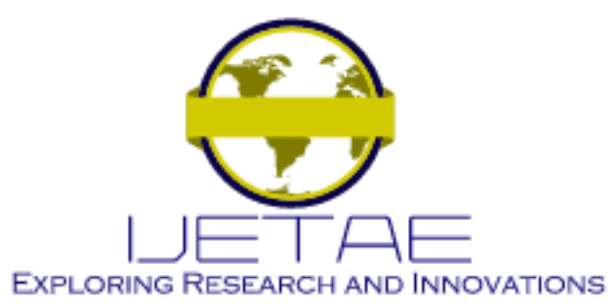

International Journal of Emerging Technology and Advanced Engineering

Website: www.ijetae.com (E-ISSN 2250-2459, Scopus Indexed, ISO 9001:2008 Certified Journal, Volume 11, Issue 10, October 2021)

c) [Assumption 3: Supposed that the cost $C_{3}$ is twice increased in Assumption 1]

$E_{1}=50 \$, C_{2}=5 \$, C_{3}=3 \$, C_{4}=10 \$, t^{\prime}=50 \mathrm{H}$

[Assumption 3] is a case where the software cost $\left(C_{\mathrm{a}}\right)$ is twice increased in [Assumption 1].

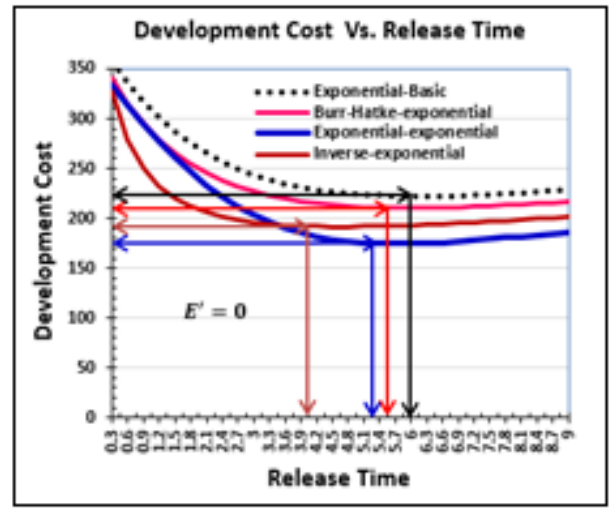

Figure 4. The Development Cost Test Simulated by [Assumption 3]

Figure 4 shows that development costs have increased, but release times have not changed at all. Therefore, to remove the cause of the development cost increase, it is necessary to eliminate as many flaws as possible at once.

d) [Assumption 4: Supposed that the cost is twice increased in Assumption 1]

$E_{1}=50 \$, C_{2}=5 \$, \quad C_{2}=1.5 \$, C_{4}=20 \$, t^{\prime}=50 \mathrm{H}$

[Assumption 4] is a case where the software cost (is twice increased in [Assumption 1].

As shown in Figure 5, it can be seen that both the development cost and the release time increased together.

Therefore, in this case, all possible defects should be eliminated during the testing process rather than the operating phase to remove all flaws before the software is released [19].

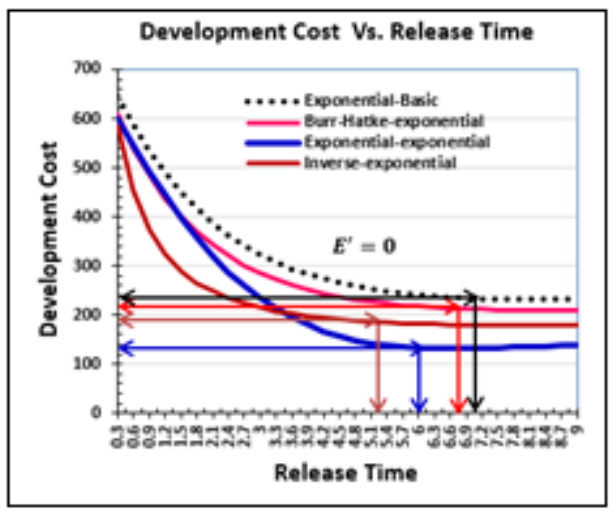

Figure 5. The Development Cost Test Simulated by [Assumption 4]

Also, the Exponential-exponential model showed the best performance because the development cost was low and the time was relatively fast.

e) [Assumption 5: Supposed that the time t' is twice increased in Assumption 1]

$E_{1}=50 \$, C_{2}=5 \$, C_{\mathrm{a}}=1.5 \$, C_{4}=10 \$, t^{\prime \prime}=100 \mathrm{H}$

[Assumption 5] is a case where the time ( $\left.\mathrm{t}^{\prime}\right)$ that the software system solution can be operated normally after releasing the software is twice increased in [Assumption 1].

As shown in Figure 6, it can be seen that the simulation result of assumption 5 is the same as the result of assumption 1 (basic condition).

That is, as the time of t' increases, the cost increases, but the cost is almost the same after the optimal release time.

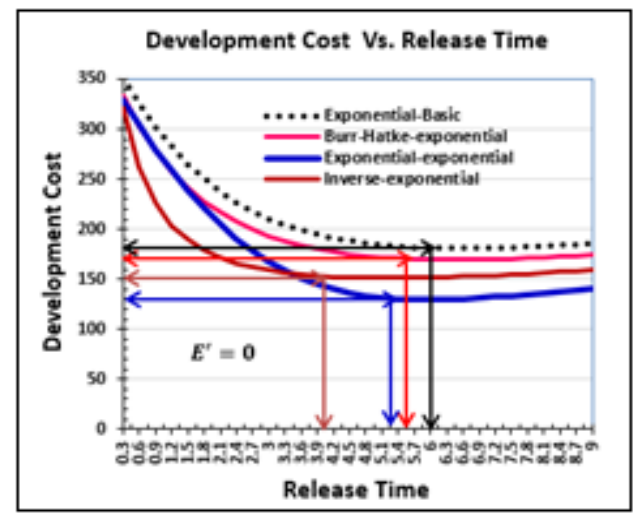

Figure 6. The Development Cost Test Simulated by [Assumption 5] 


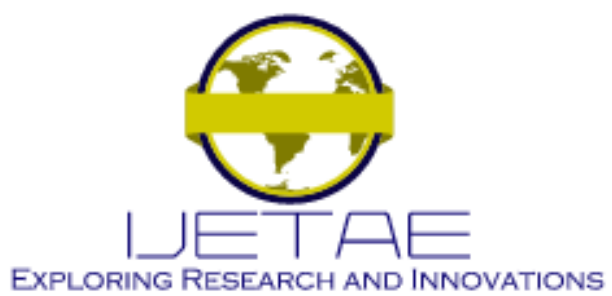

International Journal of Emerging Technology and Advanced Engineering Website: www.ijetae.com (E-ISSN 2250-2459, Scopus Indexed, ISO 9001:2008 Certified Journal, Volume 11, Issue 10, October 2021)

E. Step 5: Analyzing the future reliability attributes of the proposed models by using the mean value function.

In this paper, to verify the property of the software development cost model, future reliability analysis was also performed using the average value function of the proposed distribution models.

Table 5 shows how to calculate future reliability using the mean value function.

Table 5

Future Reliability Calculation Using Mean Value Function

\begin{tabular}{|c||c|}
\hline NHPP Model & $\begin{array}{c}\hat{R}(t) \text { using the mean value } \\
\text { function } \mathbf{m}(\mathrm{t})\end{array}$ \\
\hline \hline Exponential-Basic & \\
\cline { 1 - 2 } Exponential-exponential & $\begin{array}{l}\exp [-\{m(t+\tau)-(t)\}] \\
=\exp \left[-\left\{m\left(x_{n}+\tau\right)-\left(x_{n}\right)\right\}\right]\end{array}$ \\
\hline Inverse-exponential & \\
\cline { 1 - 2 } Burr-Hatke-exponential & \\
\hline
\end{tabular}

The calculating method of the mean value function that determines the future reliability of software development cost is shown in Table 5.

Where, the future reliability $\hat{R}(t)$ is the probability that a software error will occur and no software error will occur between the confidence intervals when testing at $t=x_{n}=738.68 \times 10^{-2}=7.38$ (where $\tau$ is the future mission time) [20].

$$
\begin{aligned}
\widehat{R}\left(\tau \mid x_{n}\right) & =e^{-\int_{x_{n}}^{x_{n+\tau}} \lambda(\tau) d \tau} \\
& =\exp \left[-\left\{m\left(x_{n}+\tau\right)-\left(x_{n}\right)\right\}\right] \\
& =\exp [-\{m(7.3868+\tau)-m(7.3868)\}]
\end{aligned}
$$

Here, the larger the reliability value, the better the reliability performance.

As shown in Fig 7, the Exponential-exponential distribution model showed higher predictive ability than the other models whose future reliability decreased with mission time passing.

That is, in terms of reliability, the Exponentialexponential distribution model is further reliable than the other models because of the highest reliability.

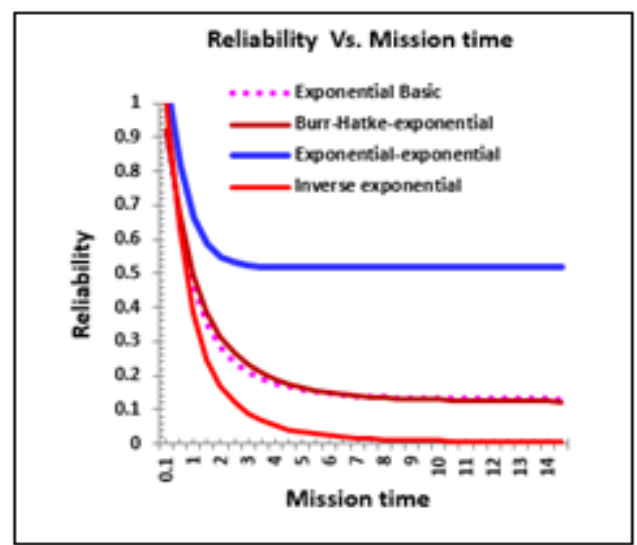

Figure 7. The Future Reliability Prediction

F. Step 6: Determining the best performance model that meets both software development cost and future reliability.

The Exponential-exponential distribution model showed the best performance because it had lower development costs and reliable reliability than other distribution models (Burr-Hatke-exponential, Exponential-Basic, Inverseexponential).

In conclusion, if using this data, we can analyze the software development cost trends, and software operators are considered to be helpful to predict the economic development costs

\section{CONCLUSIONS}

If the software development cost can be quantitatively modeled during the software testing process, it is possible to efficiently analyze and predict the attributes of the development cost. Therefore, in this study, development cost was analyzed and predicted based on the Exponentialtype distribution using the software development cost model.

The results of this study are as follows.

First (in Assumption 1), the software development cost test pattern initially decreased and then showed a constant shape for a short time, but showed a shape that increased again in the latter. The reason is that in the process of removing the flaws, the number of remaining flaws gradually decreases so that the probability of finding the residual defects decreases. Therefore, the cost eventually increases. 


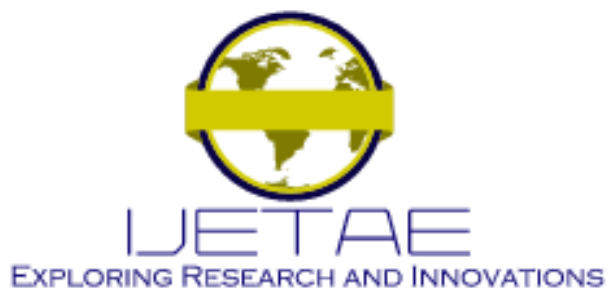

International Journal of Emerging Technology and Advanced Engineering

Website: www.ijetae.com (E-ISSN 2250-2459, Scopus Indexed, ISO 9001:2008 Certified Journal, Volume 11, Issue 10, October 2021)

Second, when the cost of removing a single flaw found during the test process increases, the development cost increases but the release time does not change at all. However, when the cost of correcting the flaws found by the operator increases, both the development cost and the release time increase together.

Third, in terms of future reliability, the Exponentialexponential distribution model is further reliable than the other models because of the highest reliability.

Fourth, the Exponential-exponential distribution model showed the best performance among the proposed models because it had the lowest software development cost and relatively fast release time.

In conclusion, as a result of comprehensively analyzing these simulation results, the Exponential-exponential model showed the best performance among the proposed Exponential-type distributions.

In addition, after applying the software failure time data applied in this study to various distribution models, future research topics to find the optimal development cost model will be needed.

\section{Acknowledgements}

Funding for this paper was provided by Namseoul University.

\section{REFERENCES}

[1] Kuo L. and Yang, T. Y., "Bayesian Computation of Software Reliability", Journal of the American Statistical Association, Vol. 91, 1996, pp. 763-773.

[2] Yang, T. J. "A Comparative Study on Reliability Attributes of Software Reliability Model Based on Type-2 Gumbel and Erlang Life Distribution", ARPN Journal of Engineering and Applied Sciences, Vol. 14, No. 10, 2019, pp. 3366-3370.

[3] Pham, H. "Distribution Function and Its Application in Software Reliability", International Journal of Performability Engineering, Vol.15, No. 5, 2019, pp. 1306-1313.

[4] Banga M, Bansal A, Singh A, "Proposed Hybrid Approach to predict Software Fault Detection", International Journal of Performability Engineering, Vol. 15, No. 8, 2019, pp. 2049-2061.

[5] Dohi T, Suzuki H, Osaki S, "Transient Analysis of NonMarkovian Software system with Rejuvenation", International Journal of Performability Engineering, Vol. 12, No. 3, 2006, pp. 233-243.

[6] Pham H, Zhang X., "NHPP Software Reliability and Cost Models with testing coverage", Eur. J. Oper. Res, Vol. 145, 2003, pp. $445-454$
[7] Kim, H. C. Shin, H. C, "A Comparative Study of Software Optimal Release Time based on Gamma Exponential and Non-exponential Family Distribution Model", Journal of Korea Society of Computer and Information, Vol. 15, No. 5, 2010, pp. 125-132.

[8] Kim, H. C. "A Study on Attribute Analysis of Software Development Cost Model about Life Distribution Considering Shape Parameter of Weibull Distribution"', The Journal of Korea Institute of Information \& Electronic Communication, Vol. 11, No. 6, 2018, pp. 645-650.

[9] Yang, T. J. "A Comparative Study on the Performance Attributes of Finite Failure NHPP Software Reliability Model with Logistic Distribution Property", International Journal of Engineering Research and Technology, Vol. 13, No. 3, 2020, pp. 438-443.

[10] Goel A L, Okumoto K, "Time-dependent Fault Detection Rate Model for Software and Other Performance Measures", IEEE Transactions on Software Engineering, Vol. 28, 1978, pp. 206-211.

[11] Kim, H. C. Choi, Y. S. Park, J. G. "An Approach for the NHPP Software Reliability Model Using Erlang Distribution”, The Journal of the Korea Institute of Maritime Information \& Communication Sciences, Vol. 10, No. 1, 2006, pp. 7-14.

[12] Kim, H. C., "A Study on the Utility of Finite-fault NHPP Software Reliability Model Applying Pareto Distribution Feature", Asiapacific Journal of Multimedia Service, Vol. 7, No. 10, 2017, pp. 915 $-923$.

[13] Zhang, Y., and Wu, K., "Software Cost Model Considering Reliability and Time of Software in Use", Journal of Convergence Information Technology, Vol. 7, No. 13, 2012, pp.135-142.

[14] R. Satya Prasad, K. R. H. Rao, and R.R.L Kantha, "Software Reliability Measuring using Modified Maximum Likelihood Estimation and SPC", International Journal of Computer Applications (0975-8887), Vol. 21, No. 7, 2011, pp. 1-5.

[15] Kuei-Chen, C., Yu-Shiang, H. and Tzai-Zang, L., "A Study of Software reliability growth from the perspective of learning effects", Reliability Engineering and System Safety 93, 2008, pp. 1410-1421.

[16] Yang, T. J. "Comparative Study on the Performance Attributes of NHPP Software Reliability Model based on Weibull Family Distribution", International Journal of Performability Engineering, Vol. 17, No.4, 2021, pp. 343-353.

[17] Yang, T. J. "A Comparative study on the Cost and Release Time of Software Development Model Based on Lindley-Type Distribution", International Journal of Engineering Research and Technology, Vol. 13, No. 9, 2020, pp. 2185-2190.

[18] Ma, B. and Wan, Z. Hu, Z. Li, Zhantong,.., "Application of Simulation Software in Optimization of Powertrain of Pure Electric Vehicle", International Journal of Emerging Technology and Advanced Engineering, Vol. 10, No. 11, 2020, pp. 42-55.

[19] Abd Raham, A.S.A and Masrom, S. Abdul Raham, Rahayu. Ibrahim, R. "Rapid Software Framework for the Implementation of Machine Learning Classification Models", International Journal of Emerging Technology and Advanced Engineering, Vol. 11, No. 08, 2021, pp. 8-18.

[20] Yang, T. J. "A Study on the Reliability Performance Analysis of Finite Failure NHPP Software Reliability Model Based on Weibull Life Distribution", International Journal of Engineering Research and Technology, Vol.12, No. 11, 2019, pp. 1890-1896. 